\title{
(2) OPEN ACCESS \\ Variations in cigarette brand characteristics: can consumers tell the difference?
}

\author{
Jeroen L A Pennings (1) , ${ }^{1}$ Geoffrey Ferris Wayne, ${ }^{2}$ Walther N M Klerx, \\ Charlotte G G M Pauwels (1), ${ }^{1}$ Reinskje Talhout ${ }^{1}$
}

\begin{abstract}
- Additional supplemental material is published online only. To view, please visit the journal online (http://dx.doi. org/10.1136/tobaccocontrol2021-056856).
\end{abstract}

${ }^{1}$ Centre for Health Protection, National Institute for Public Health and the Environment (RIVM), Bilthoven, The Netherlands

${ }^{2}$ WiseDesign, Vienna, Virginia, USA

\section{Correspondence to} Dr Jeroen L A Pennings, National Institute for Public Health and the Environment (RIVM), 3721MA Bilthoven, Netherlands; jeroen.pennings@rivm.nl

Received 17 June 2021 Accepted 9 November 2021

\begin{abstract}
Objectives Sensory experience is an important determinant of smoking initiation, brand choice and harm perception, but little is known about how cigarette design shapes sensory experience. This study reports which variations in tobacco blend and design characteristics available on the market are likely to be perceived as different by consumers.
\end{abstract}

Methods Truth Tobacco Industry Documents was reviewed for studies showing noticeable sensory differences resulting from variations in tobacco blend and design characteristics. These differences were compared with tobacco product data as available in the Dutch section of the European Common Entry Gate (EUCEG) system on 30 April 2020.

Results Industry documents identified discrimination thresholds for ventilation, pressure drop, tobacco weight, filter length, and tar and nicotine levels in smoke while evidence for other design characteristics was less conclusive. In the 103 different cigarette varieties in the EU-CEG database, five main types of cigarettes could be identified by principal component analysis, differing in (combinations of) design characteristics. The most significant differences between brand varieties were tar, nicotine and carbon monoxide emissions and associated parameters filter ventilation, filter length, cigarette length and tobacco weight.

Conclusions While some clusters of brand varieties provided a noticeably different product for consumers, in many cases design differences within these clusters did not exceed the expected discrimination threshold. This indicates that many products on the market are not discernibly different for consumers, and that proliferation of brand varieties has a non-sensory purpose, such as marketing. Policy makers should consider limiting available brand varieties and regulating design characteristics to reduce product appeal.

\section{INTRODUCTION}

The sensory experience of smoking plays an important role in smoking initiation, brand choice and harm perception of cigarette brands. ${ }^{12}$ Therefore, the tobacco industry devotes considerable resources to sensory evaluation of their products. ${ }^{3}$ Trained panellists or consumers describe their sensory experience, test whether they can discriminate products or score products on hedonic properties such as liking. Internal tobacco industry documents show that product appeal and inhalation intensity are mainly determined by the harshnesssmoothness balance, non-irritant sensory responses such as taste and satisfaction, and resistance to draw (RTD) ${ }^{4}$
The modern cigarette market supplies many brands and types differing in their design characteristics. Variations in tobacco type, additives and physical design characteristics, most notably filter ventilation, determine smoke sensory perception. $^{245}$ It is well known that tobacco additives, especially flavours, increase appeal and inhalation intensity, and therefore flavours or flavourings are regulated in some jurisdictions. ${ }^{67}$ For example, subjective ratings associated with taste and smell are significantly higher for menthol cigarettes, ${ }^{8}$ and perceived 'strength of menthol taste' and 'cooling' effect are dose dependent on the menthol level.' Filter ventilation has also been well studied. For consumers, higher degrees of filter ventilation lead to a lighter tasting, and milder and less irritating smoke. ${ }^{5}{ }^{10-12}$ Relatively few peer-reviewed studies have been published on the sensory effects of variations in other cigarette design characteristics. With limited exceptions, it is not known which differences can be discriminated.

While smokers could make distinctions between different types of cigarettes, they were generally not able to choose their own brand among others. ${ }^{13}$ Brands with higher nicotine yields could be distinguished from brands with lower yields, and flattasting cigarettes from sharp-tasting cigarettes. Although these differences were not explained in terms of design characteristics, two brands in the flat-low nicotine range were 'lights', meaning they were probably high-ventilation cigarettes. Moreover, cigarettes with different nicotine yields could be discriminated, but nicotine was not the only factor determining sensory intensity and taste. ${ }^{14}$ Finally, harshness of smoke was higher in the dark tobacco category and generally decreased with the lower smoke yield cigarettes. ${ }^{15}$

Given the large variety of products available on the market, the question arises which variations in cigarette design characteristics can actually be perceived as different by consumers. The current paper addresses this question using commercially available brands on the Dutch market as a case. Industry documents were reviewed for studies showing noticeable sensory differences resulting from variations in tobacco blend and design characteristics. These differences were compared with data on tobacco blend and design characteristics sent to the Dutch authorities via the European Common Entry Gate (EU-CEG). ${ }^{16}$ Our findings will inform regulators on the most prominent design characteristics that influence consumer sensory perception of cigarette smoke, and their prevalence on the Dutch market. Regulators can compare the noticeable 
sensory differences identified in the industry documents, which apply to all markets, to design characteristic data in their own national markets.

\section{METHODS}

\section{Tobacco document review}

Iterative keyword-based document searches were conducted online between 1 October and 15 December 2020 in the Truth Tobacco Industry Documents archive hosted at the University of California-San Francisco. ${ }^{17}$ Further details can be found in the online supplemental file.

\section{Product data analysis}

For analyses of EU-CEG cigarette data, we used tobacco product data as available in the Dutch section of the EU-CEG system ${ }^{16}$ on 30 April 2020. Further details can be found in the online supplemental file.

To assess mutual dependencies between product parameters, we determined Spearman correlations. For multivariate comparisons of product data between brands and brand varieties, we visualised data by principal component analysis (PCA) and identified product-type clusters. Discrimination threshold values based on industry documents were used to draw grids. For tobacco blend, no clear threshold emerged from the industry documents and therefore the largest non-detectable difference was used.

\section{Filter ventilation control measurements}

To independently evaluate the accuracy of the data in the EU-CEG database, the filter length, filter pressure drop (PD) open and closed and the filter ventilation were measured in 56 different cigarette brand varieties. Filter PD and filter ventilation were measured according to International Organization for Standardization (ISO) 6565 and ISO 9512, respectively. ${ }^{18} 19$

\section{RESULTS}

\section{Internal tobacco industry document data}

A total of 81 studies describing a discrimination threshold of noticeable sensory differences were identified. A description of the types of studies used by manufacturers to compare differences in perception across products is provided in the online supplemental files 1-3. A summary of these findings, organised by physical design parameters, is provided in table 1 . A more detailed description of individual documents, including references, is provided in online supplemental table 1 . Table 1 presents a potential threshold range for discrimination for each product characteristic. It should be noted that the evidence indicates linear rather than categorical differences, with no single distinct tipping point with respect to discrimination. ${ }^{20}$ Further, measures of discrimination may differ with respect to individuals and between populations of smokers (eg, full flavour vs low tar). ${ }^{21}$ Interactions among some physical product characteristics (eg, ventilation and PD) are inherent; however, the studies included were those that attempted to control for interactions and/or limited product differences to support comparisons of specific design characteristics.

Twenty-five studies were identified that evaluated the discrimination of products that differed on the basis of ventilation (ie, per cent of smoke diluted with air due to the addition of holes in the filter). The studies were evenly distributed across expert and consumer panels, and the majority were paired comparisons, although four studies were dependent on factorial analyses applied to a series of separate monadic assessments. Findings were strongly consistent across studies, with ventilation differences of less than $10 \%$ generally not identified by smokers, and differences of $12 \%$ or greater perceived as significantly different. This pattern held across all levels of ventilation tested, although most tests were between 0\% and 50\% ventilation. A 1983 British American Tobacco study estimating effect sizes of ventilation changes independent of other product variables indicates a detection threshold between $10 \%$ and $12 \% .^{22}$ An exception, a 2000 RJ Reynolds Tobacco expert panel study, identified significant perceptual differences at ventilation increments below $10 \%$ reflecting a perceived change in draw characteristics, ${ }^{23}$ underscoring the potential interactions between perceptions of ventilation and draw.

While fewer studies (13) of PD (also called RTD) were identified, most were well designed and made an effort to isolate the potential impact of other design variables. Reported values here are closed PD normalised to millimetres (usually reported as $\mathrm{mmWg}$ ), similar findings were presented for other PD measures. Threshold for discrimination was around $15-20 \mathrm{~mm}$, where differences less than $15 \mathrm{~mm}$ were unidentifiable by smokers, and differences larger than $20 \mathrm{~mm}$ were identified in many (but not all) cases. Most products were in the range of 100-140 mm $\mathrm{PD}$, indicating a difference of more than $10 \%-15 \%$, which was consistent across the range of products tested. Studies indicated that behavioural differences (ie, changes to puff topography)

\begin{tabular}{|c|c|c|c|c|c|}
\hline Category & Threshold for discrimination & Evidence & Studies & Type of studies & Test panels \\
\hline Ventilation & $10 \%-12 \%$ difference & Strong, consistent & 25 & $\mathrm{PC}, \mathrm{MC}$ & $C P, E P$ \\
\hline Pressure drop* & $\begin{array}{l}15-20 \mathrm{~mm} \text { difference } \\
(10 \%-15 \%)\end{array}$ & Strong, consistent & 13 & $\mathrm{PC}, \mathrm{MC}$ & $C P, E P$ \\
\hline Tobacco weight & $\begin{array}{l}40-60 \mathrm{mg} \text { difference } \\
\text { (6\%-8\% of tobacco weight) }\end{array}$ & Good, consistent & 10 & FA & $C P, E P, A P$ \\
\hline Cigarette length & $1-2 \mathrm{~mm}$ difference $(2 \%)$ & Limited & 3 & IM & AP \\
\hline Filter length & $\begin{array}{l}1-3.5 \mathrm{~mm} \text { difference } \\
(10 \%-15 \%)\end{array}$ & Good, consistent & 9 & $\mathrm{PC}, \mathrm{MC}, \mathrm{TD}, \mathrm{R}$ & $C P, E P$ \\
\hline Circumference & $\leq 1 \mathrm{~mm}$ diameter change ( $4 \%$ difference) & Limited & 4 & $M C, R$, FA, IM & $\mathrm{CP}, \mathrm{EP}, \mathrm{MI}$ \\
\hline Density & $13 \mathrm{mg} / \mathrm{cm}^{3}$ & (Very) limited & 2 & MC, FA & EP \\
\hline Tobacco blend & $\leq 10 \%$ change in blend components & Moderate, not consistent & 15 & $P C, M C, T D, R, F A$ & $C P, E P$ \\
\hline
\end{tabular}

${ }^{*}$ Closed PD, whole cigarette. Evidence descriptor (strong/good/moderate/limited) weights number of studies by strength of study design and reliability; consistency indicates agreement among studies ( $>5$ only).

AP, ad hoc panel; CP, consumer panel; EP, expert panel; FA, factorial analysis; IM, implementation; MC, monadic comparison; MI, mall interview; PC, paired comparison; PD, pressure drop; R, review (multiple studies); TD, triangle discrimination. 
were also measurable in response to PD changes and occurred in the same general range as sensory differences.

Studies of tobacco weight differences (10) were primarily conducted among expert panellists and included both monadic and paired comparisons. Tobacco weights generally ranged from 650 to $850 \mathrm{mg}$, with one study comparing products of $850-1050$ $\mathrm{mg}$. While most product discrimination occurred above $50 \mathrm{mg}$ differences, discrimination outcomes were not consistent for differences in the 30-50 mg range. A monadic-based factorial analysis concluded that $6 \%$ weight reduction was not discriminable. ${ }^{24}$ Other studies indicate a threshold between $4 \%$ and $8 \%$.

Studies of product dimensions including cigarette length and circumference focused on small (ie, visually imperceptible) differences, in the order of $1 \%-2 \%$, such as differences of $1-2$ $\mathrm{mm}$ length (in a $100 \mathrm{~mm}$ cigarette), and $0.2-0.3 \mathrm{~mm}$ differences in a $25 \mathrm{~mm}$ circumference. In all cases, these differences were below detection threshold, and more sizeable differences were not assessed. Filter length was considered on a wider scale, primarily as a cost reduction measure. ${ }^{25}{ }^{26}$ Differences from 1 to $3.5 \mathrm{~mm}$ were evaluated across consumer studies in products with filter lengths from 13 to $31 \mathrm{~mm}$ (ie, in the range of 10\%-15\% difference). In nearly all cases, differences were not identifiable by smokers. In two exceptions, a $2 \mathrm{~mm}$ difference in filter length resulted in a small but measurable difference in taste perception, although preference remained unchanged. ${ }^{27} 28$

While a large number of studies (16) were identified on tobacco blend, product changes tended to include a range of blend characteristics, complicating interpretation of findings. Consistently, however, differences in blend ratios of less than $10 \%$ were not discriminable by smokers. This included addition of reconstituted or expanded tobacco to the blend, as well as changes in ratio of flue-cured, burley and oriental tobaccos. Discrimination of larger blend changes was inconsistent. Differences of $15 \%$ or more in both flue cured and burley (as percentage of total blend) remained undetectable in two separate studies. ${ }^{29}{ }^{30}$ On the other hand, inclusion of expanded tobacco at levels of greater than $10 \%$ was identifiable by smokers. ${ }^{31} 32$

Comprehensive studies were conducted on discrimination of nicotine in tobacco, as well as smoke machine measured tar and nicotine delivery. A difference threshold for tar was identified at $0.7 \mathrm{mg}(\sim 10 \%)$, although product acceptance and quality control limits were $1 \mathrm{mg}$ or greater. ${ }^{33}{ }^{34}$ A threshold study for smoke nicotine found that a change of $0.2 \mathrm{mg}$ nicotine in smoke $(10 \%-15 \%)$ was needed for $10 \%$ of the population to identify a difference (called just noticeable difference or JND10). ${ }^{35}$ Another summary review comprising multiple studies identified a threshold value for smoke nicotine of $6 \%$, but observed that larger differences would be masked by higher tar levels. ${ }^{36}$

\section{European Common Entry Gate}

Using EU-CEG and Dutch market data, we identified 103 cigarette varieties that were available in the Dutch market at the time of the analyses. These belong to 33 brands, with the number of varieties per brand ranging from 1 to 12 (table 2). Eight brands with five varieties or more together contributed to the majority (57) of all brand varieties. Two products that were sold under different brand names but are otherwise identical have been listed under both their brand names in table 2, but used only once for data analyses.

By using analysis of variance to compare within-brand variation to the total variation, we found 14 parameters that had a large role in variation between brand varieties. These mainly concern physical product measures (length, filter length, tobacco
Table 2 Number of varieties on the Dutch market per brand

\begin{tabular}{ll}
\hline Varieties $(\mathbf{n})$ & Brand(s) \\
\hline 12 & Marlboro \\
\hline 9 & JPS \\
7 & Camel, Gauloises \\
6 & Dunhill, Lucky Strike \\
5 & Pall Mall, Winston \\
\hline 4 & Davidoff, Karelia, Peter Stuyvesant \\
\hline 3 & Elixyr, L\&M \\
\hline 1 & American Spirit, Benson \& Hedges, Black Devil, Kent, \\
& Kornet, Mark Adams, Mohawk, Pueblo, Ruba, Titaan \\
& Apache, Bastos, Caballero, Chesterfield, Lambert \& Butler, \\
& Regal, Silk Cut, Superkings, Texas, Vogue \\
\hline
\end{tabular}

weight), filter ventilation (FilterVentilation, FilterDropPressureOpen) and tar, nicotine and carbon monoxide (TNCO) emissions. There were 16 parameters with a small role for variation between brand varieties. These parameters concern tobacco blend $(n=6)$ and the number of additives $(n=10)$. A full overview of product parameter data and summary statistics is shown in Online supplemental table 2.

Nicotine emissions as generated with the ISO smoking protocol strongly depended on filter ventilation. A linear prediction model based on filter ventilation alone predicted nicotine levels with $\mathrm{R}=0.70$. On adding parameters, the best overall model included filter ventilation, tobacco weight and diameter; this model predicted nicotine emissions with $\mathrm{R}=0.74$.

PCA indicated that five types of product could be identified, namely low-TNCO cigarettes (low-TNCO emissions, high filter ventilation), British-style cigarettes (high content of flue-cured tobacco, few flavour additives), American blend cigarettes (more tobacco additives), American blend cigarettes by Philip Morris (more tobacco additives, more expanded tobacco, low PD) and dark tobacco cigarettes (low content of flue-cured tobacco, few flavour additives, low PD, low filter ventilation).

Based on the PCA variable loadings, we found that PC1 related to TNCO and filter ventilation, PC2 to tobacco blend (leaf type and cure method), PC3 to PD closed and expanded tobacco and PC4 to tobacco weight and correlated parameters such as length. Considering our findings from the industry tobacco document review, we selected four parameters for further visualisation, namely: filter ventilation, percentage flue-cured tobacco, filter PD closed and tobacco weight.

Plots for these product characteristics, combined with discrimination thresholds (figure 1, online supplemental figure 1 ), illustrate that brands, and to a lesser extent brand varieties, can partly be distinguished by their relative position. The six brands with the largest number of brand varieties (Marlboro, JPS, Camel, Gauloises, Dunhill, Lucky Strike) tended to have less within-brand variation compared with the overall market (the median value of their within-brand variation was $21 \%$ of the total market variation).

\section{Filter ventilation control measurements}

The results of the measurements and EU-CEG data are shown in online supplemental table 3. EU-CEG data agreed reasonably well with the measured data, with some exceptions. In 17 products one or more of the checked parameters were $>120 \%$ of the EU-CEG data, and in 12 products one or more of the checked parameters were $<80 \%$ of the EU-CEG data. Exceptional differences were found in 10 cases, where the measured 
A

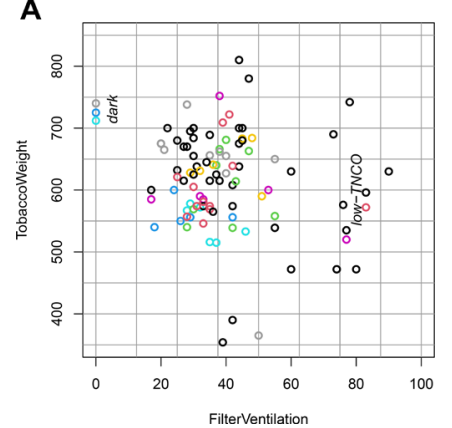

B

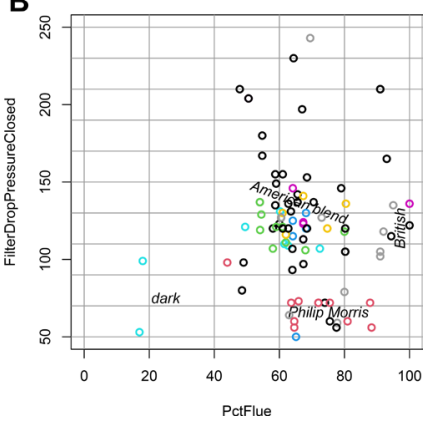

Figure 1 Plots for comparing cigarette types and brand varieties based on product characteristics and their discrimination thresholds. (A) Filter ventilation versus tobacco weight and (B) percentage flue-cured tobacco versus filter PD closed. A full overview of product characteristic plots is shown in online supplemental figure 1. Coloured dots indicate different brands with five or more varieties; black dots indicate brands with two to four varieties; grey dots indicate brands with a single variety. Grey lines are spaced by consumer discrimination thresholds. The approximate region of cigarette types is indicated as italic text. TNCO, tar, nicotine and carbon monoxide.

PD closed was $>150 \%$ of the EU-CEG data and in one case the filter ventilation was $<50 \%$ of the EU-CEG data.

\section{DISCUSSION}

\section{Contributions of the paper}

Our study examines which variations in cigarette design characteristics in the Dutch market are likely to be perceived as different by consumers. We searched the Truth Tobacco Industry Documents to determine which parameters are important for consumer sensory perception of cigarette smoke and which differences can be discriminated by consumers. Additionally, we used EU-CEG data to determine how parameters vary within and between brands. Based on this, we visualised the data to judge which differences are noticeable by consumers.

Tobacco industry discrimination studies as identified in the present review focused on the design parameters of filter ventilation, PD, tobacco weight and tobacco blend, with only limited research found on other physical parameters. Within these main parameters, discrimination thresholds were consistently identified, with absolute parameter differences of $10 \%-15 \%$ generally needed to support consumer perception (or 6\%-8\% in the case of tobacco weight). Although the documents cited are now decades old, their findings are consistent across multiple time periods and manufacturers; and the design parameters that they describe remain within the same general range as those identified in the current Dutch market. The findings describe the general population of smokers, and further research would be necessary to address specific populations such as naïve users and to assess the influence of factors such as smoking history, gender or level of dependence.

Perceptual interactions among different parameters can be complicated to untangle and some identified discrimination thresholds may vary as a result of parameter interactions. Nonetheless, as indicated by the EU-CEG data (figure 1), many or most cigarette products on the Dutch market are clustered within a limited band of physical parameter measures, with the result that such products will not be perceived as distinguishable by many consumers.

Our results show that in the Netherlands, differences between brand varieties can mainly be found in TNCO emissions and

associated parameters cigarette length, filter length, tobacco weight and, especially, filter ventilation. In most cases, differences between brand varieties were smaller than the threshold for discrimination by consumers. This would suggest that most brand varieties, and indeed some brands, will be difficult to discriminate by consumers, with the exceptions of low-TNCO cigarettes. Our plots also indicated different market positionings for brand names with only a single variety, as here too, several types could be distinguished based on product parameters and plot position. Some single-product brands are similar to other products by the same manufacturer (eg, Chesterfield to Marlboro). Others seem to target a market niche, for example, 'dark tobacco' (such as Caballero) or British-style cigarettes (such as Lambert \& Butler).

TNCO emissions are not design parameters by themselves. Instead, related physical parameters such as filter ventilation are tuned to give a desired outcome, regarding consumer sensory perception, manufacturing costs and-in the case of filter ventilation-TNCO values as measured under ISO machine smoking regimes for regulatory purposes. ${ }^{10}$ We found that filter ventilation determined $70 \%$ of the TNCO levels as measured with ISO. More intense smoking methods such as the Canadian Intense better reflect human behaviour in response to filter ventilation, such as more intense puffing and vent blocking, but such data are currently not legally required by the European Tobacco Products Directive (TPD). It should be noted that the Tobacco Products Directive prescribes upper limits of $10 \mathrm{mg}$ tar, $1 \mathrm{mg}$ nicotine and $10 \mathrm{mg} \mathrm{CO} .{ }^{6}$ In other countries, without such limits, the variation in TNCO levels will probably be higher, with the effect that the observed variety in cigarette characteristics may be higher than in the Netherlands. Given potential market differences, we recommend that researchers in other countries, where similar data are available, conduct comparable studies on the variation of design characteristics in their own markets.

We found that some brand varieties provide a noticeably different product for consumers, such as a low-TNCO version, but in most cases the differences are relatively small and typically did not exceed the threshold for consumers.

\section{Limitations}

While our EU-CEG analysis included the number of additives per function, we did not look at which specific additives were used or whether additive differences may be distinguished by consumers, as the complexity of additives and additive properties exceeded the scope of this paper. Further, characterising flavours have been banned in the European Union since 2016, and menthol since $2020,{ }^{6}$ limiting the potential for flavours to serve as recognisable differentiators among products. Brand varieties show relatively little variation in tobacco composition and the number of additives. A limited analysis of additives suggests some aspects that appear more related to presentation (inks used on cigarette paper, filter overwrap, tipping paper and tipping paper inks) and as such are less likely to lead to sensory differences. Other parameters such as sizing agents and viscosity modifiers may lead to sensory differences by acting on parameters such as PD, although we did not see a clear correlation. Overall, tobacco composition and additives show some differences between brands, although it is not clear to what extent they can be discriminated by consumers.

The data used for this study were submitted to EU-CEG by manufacturers as part of their mandatory reporting to national authorities. Because it is not always feasible or practical to validate that the data are correct (or entered correctly), this could be 
seen as a limitation of our data set. However, filter ventilation emerges as an important parameter from our analyses. Control measurements showed that EU-CEG data agreed well with the measured data, with some exceptions. Although we cannot extrapolate this agreement to all other parameters, there is at least some evidence that the data overall are valid.

\section{Regulatory implications}

The results of this paper show that within the Dutch market, many of the variations within and between brands may be imperceptible by consumers. Five clusters of cigarettes could be identified with different combinations of design characteristics: low-TNCO cigarettes, British-style cigarettes, American blend cigarettes, American blend cigarettes by Philip Morris and dark tobacco cigarettes. The striking similarities in design characteristics across multiple products may suggest that certain combinations of cigarette parameters appeal to different types of smokers. Cases in which a brand places several products within the same cluster indicate that brand variety is not always motivated by sensory differences but may also serve as a means to provide choice options and target specific subgroups as, for example, through brand image.

By comparing data presented in this study with data from their own market, regulators can evaluate differences in brand characteristics and determine which products are likely to be perceived by smokers as different. Such an evaluation can be used as a basis to limit brand diversification, particularly in cases where no clear sensory differences are identified. For example, regulations could set limits on introduction of new brand variants that fall within the range of characteristics of products already on the market. Alternately, differences in product characteristics as identified in the present study could be used to inform evaluation of proposed product changes, as under the US Food and Drug Administration substantial equivalence pathway, and trigger more thorough review. Regulators may also wish to consider whether product clusters such as those identified in the present study represent ideal constructions to support tobacco use and may be a target for efforts to reduce cigarette appeal.

\section{What this paper adds}

- The modern cigarette market supplies many brands and types differing in their design characteristics such as filter ventilation and tobacco blend.

- Little is known about how design characteristics affect users' sensory experience.

- Our study is the first to examine which variations in design characteristics available on the market are likely to be perceived as different by consumers using a combination of Truth Tobacco Industry Documents and European Common Entry Gate industry data of the Dutch market.

- We found five clusters of cigarettes with different combinations of design characteristics. Within these clusters, differences between cigarettes will most likely not be noticeable by consumers.

- This may suggest that these five combinations of design characteristics appeal to different types of smokers. Proliferation of brand varieties within these clusters may instead play a marketing role.

- Based on our findings, regulators should consider limiting available brand varieties and regulating design characteristics to reduce product appeal.

\section{CONCLUSIONS}

Among the cigarettes on the Dutch market, there are few noticeable differences between brands and brand variations, with the exception of the five clusters that correspond to different types of cigarettes. While some brand varieties provide a noticeably different product for consumers, such as a low-TNCO version, in most cases the differences are relatively small. Thus, proliferation of brand varieties within these clusters may play a marketing role rather than representing discernibly different products to consumers.

Acknowledgements The authors would like to thank Peter Keizers and Lotte van Nierop for their critical review of the manuscript.

Contributors RT conceived the research idea, secured funding and acts as guarantor for the study. All authors contributed to the research plan and drafting of the manuscript. JLAP carried out the product data analyses. GFW and CGGMP searched the tobacco industry documents and reviewed the results. WNMK measured the filter ventilation. All authors approved the final version for publication.

Funding This project was funded by the Netherlands Food and Consumer Product Safety Authority (NVWA) (project 9.7.1).

Competing interests None declared.

Patient consent for publication Not required.

Provenance and peer review Not commissioned; externally peer reviewed.

Data availability statement All data relevant to the study are included in the article or uploaded as supplementary information. NA.

Open access This is an open access article distributed in accordance with the Creative Commons Attribution Non Commercial (CC BY-NC 4.0) license, which permits others to distribute, remix, adapt, build upon this work non-commercially, and license their derivative works on different terms, provided the original work is properly cited, appropriate credit is given, any changes made indicated, and the use is non-commercial. See: http://creativecommons.org/licenses/by-nc/4.0/.

\section{ORCID iDs}

Jeroen L A Pennings http://orcid.org/0000-0002-9188-6358

Charlotte G G M Pauwels http://orcid.org/0000-0001-6727-0804

\section{REFERENCES}

1 Henningfield JE, Hatsukami DK, Zeller M, et al. Conference on abuse liability and appeal of tobacco products: conclusions and recommendations. Drug Alcohol Depend 2011;116:1-7.

2 Agaku IT, Omaduvie UT, Filippidis FT, et al. Cigarette design and marketing features are associated with increased smoking susceptibility and perception of reduced harm among smokers in 27 EU countries. Tob Control 2015;24:e233-40.

3 Talhout R, van de Nobelen S, Kienhuis AS. An inventory of methods suitable to assess additive-induced characterising flavours of tobacco products. Drug Alcohol Depend 2016;161:9-14.

4 Rees VW, Kreslake JM, Wayne GF, et al. Role of cigarette sensory cues in modifying puffing topography. Drug Alcohol Depend 2012;124:1-10.

5 Talhout R, Richter PA, Stepanov I, et al. Cigarette design features: effects on emission levels, user perception, and behavior. Tob Regul Sci 2018;4:592-604.

6 European Commission. Tobacco products directive (2014/40/EU), 2014. Available: https://ec.europa.eu/health/sites/health/files/tobacco/docs/dir_201440_en.pdf

7 US Food and Drug Administration. Family Smoking Prevention and Tobacco Control Act (section 907(a)(1)(A)), 2009. Available: https://www.govinfo.gov/content/pkg/ PLAW-111 publ31/pdf/PLAW-111publ31.pdf

8 Strasser AA, Ashare RL, Kaufman M, et al. The effect of menthol on cigarette smoking behaviors, biomarkers and subjective responses. Cancer Epidemiol Biomarkers Prev 2013;22:382-9.

9 Ashley M, Dixon M, Sisodiya A, et al. Lack of effect of menthol level and type on smokers' estimated mouth level exposures to tar and nicotine and perceived sensory characteristics of cigarette smoke. Regul Toxicol Pharmacol 2012;63:381-90.

10 Kozlowski LT, O'Connor RJ. Cigarette filter ventilation is a defective design because of misleading taste, bigger puffs, and blocked vents. Tob Control 2002;11 Suppl $1: i 40-50$.

11 Cutler TJ, Nye DA. Anything but 'empowerment'? Smokers, tar and nicotine data and cigarette design. Health Risk Soc 2000;2:69-81.

12 O'Connor RJ, Caruso RV, Borland R, et al. Relationship of cigarette-related perceptions to cigarette design features: findings from the 2009 ITC U.S. survey. Nicotine Tob Res 2013;15:1943-7.

13 Jaffe AJ, Glaros AG. Taste dimensions in cigarette discrimination: a multidimensional scaling approach. Addict Behav 1986;11:407-13. 
14 Kochhar N, Warburton DM. Puff-by-puff sensory evaluation of a low to middle tar medium nicotine cigarette designed to maintain nicotine delivery to the smoker. Psychopharmacology 1990;102:343-9.

15 Nil R, Bättig K. Separate effects of cigarette smoke yield and smoke taste on smoking behavior. Psychopharmacology 1989;99:54-9.

16 European Commission. European common entry gate system. Available: https://ec. europa.eu/health/euceg/

17 Truth Initiative. Truth tobacco industry documents. Available: https://www. industrydocuments.ucsf.edu/tobacco

18 International Standardisation Organisation (ISO). ISO 6565: tobacco and tobacco products - draw resistance of cigarettes and pressure drop of filter rods - standard conditions and measurement, 2015. Available: https://www.iso.org/standard/64265. html

19 International Standardisation Organisation (ISO). ISO 9512: cigarettes determination of ventilation — definitions and measurement principles, 2019. Available: https://www.iso.org/standard/73027.html

20 Hayes C, Keene C. Brica weight series: summary of subjective investigations. 1995 Sept 13. Philip Morris records; master settlement agreement. Available: https://www. industrydocuments.ucsf.edu/tobacco/docs/\#id=mqnp0217 [Accessed 10 Feb 2021].

21 Ennis DM, Mendell S, Rowe CH. The relationship between Dilution/RTD ratios and consumer perception. 1983 June 17. product design MSA collection. Available: https://www.industrydocuments.ucsf.edu/tobacco/docs/\#id=mgvj0037 [Accessed 10 Feb 2021].

22 British-American Tobacco Company Limited. Group Research and Development Centre (Harding, BC). Effects of Ventilation and Pressure Drop Variability on the Sensory Properties of a Low Delivery Cigarette - Report Number RD 1912 Restricted. 1983 April 08. British American Tobacco Records. Available: https:// www.industrydocuments.ucsf.edu/tobacco/docs/\#id=msxx0203 [Accessed 10 Feb 2021].

23 Gordin HH. Sensory evaluation study. SPU physical variable study. Effect of total dilution on product perception. 2000 nov 27. RJ Reynolds records; master settlement agreement.. Available: https://www.industrydocuments.ucsf.edu/tobacco/docs/\#id= Iglw0186 [Accessed 10 Feb 2021].

24 Summary of 1993 (19930000) cost reduction initiatives. 1994 nov 29. RJ Reynolds records; master settlement agreement.. Available: https://www.industrydocuments. ucsf.edu/tobacco/docs/\#id=fxvc0089 [Accessed 10 Feb 2021].

25 Stanford BC. Product research report. final report $1 \mathrm{~mm}$ filter length discrimination test. 1982 AUG 17. RJ Reynolds records; master settlement agreement.. Available: https://www.industrydocuments.ucsf.edu/tobacco/docs/\#id=kspl0184 [Accessed 10 Feb 2021].
26 Snyder SL. 1980 (800000) product changes. 1980 April 30. RJ Reynolds records; master settlement agreement., 1980. Available: https://www.industrydocuments.ucsf. edu/tobacco/docs/\#id=nrpm0095 [Accessed 10 Feb 2021].

27 Geiszler WA. Filter length changes for 85 MM merit. 1981 March 05. Philip Morris records; master settlement agreement.. Available: https://www.industrydocuments. ucsf.edu/tobacco/docs/\#id=hlyj0119 [Accessed 10 Feb 2021].

28 Gordin HH. Filter length increase review of previous research. 1997 July 24. RJ Reynolds records; master settlement agreement.. Available: https://www. industrydocuments.ucsf.edu/tobacco/docs/\#id=lqmd0230 [Accessed 10 Feb 2021].

29 Gignac J. Sensory evaluation of burley and flue-cured sub-blend variation (type and level) - winston lights 85vf. 1990 March 20. RJ Reynolds Records; Master Settlement Agreement.. Available: https://www.industrydocuments.ucsf.edu/tobacco/docs/\#id= sjwd0152 [Accessed 10 Feb 2021].

30 Beatley VE, Cantile AF, Daniel HG. 4010 brand development Virginia panel test 9509 production merit menthol $100 \mathrm{~mm}$, merit AC and casing (DOAEI) vs. Merit menthol $100 \mathrm{~mm}$ with DBC bright and burley percentages reversed, merit $A C$ and casing (DOAEJ). 1980 OCT 15. Philip Morris records; master settlement agreement. Available: https://www.industrydocuments.ucsf.edu/tobacco/docs/\#id=znjd0122 [Accessed 10 Feb 2021].

310 percent G-13. 1989 nov 21. RJ Reynolds records; master settlement agreement. Available: https://www.industrydocuments.ucsf.edu/tobacco/docs/\#id=jhwm0230 [Accessed 10 Feb 2021].

32 Cantile A, Collins J, Daniel HG. Virginia panel test $554085 \mathrm{~mm}$ alpine menthol y76-4 (D9BBH) vs. 85mm alpine menthol y80-1 with 12 percent ET (D9BBI). 1979 Oct 01. Philip Morris records; master settlement agreement.. Available: https://www. industrydocuments.ucsf.edu/tobacco/docs/\#id=gtml0038 [Accessed 10 Feb 2021].

33 Air dilution control training presentation module \#1: Tar and consumer acceptance. 1983 March 15. RJ Reynolds Records; Master Settlement Agreement. Available: https://www.industrydocuments.ucsf.edu/tobacco/docs/\#id=qjgg0003 [Accessed 10 Feb 2021].

34 ULT 'tar' and air dilution variability-acceptance study. 1982 Oct 12. RJ Reynolds Records; Master Settlement Agreement:500898550-500898568.. Available: https:// www.industrydocuments.ucsf.edu/tobacco/docs/\#id=fgkc0094 [Accessed 10 Feb 2021].

35 Janjigian K, Perfetti TA, Green CR. Nicotine just noticeable difference study of full flavor non-menthol 85mm products. 1985 Sept 05. RJ Reynolds records; master settlement agreement. Available: https://www.industrydocuments.ucsf.edu/tobacco/ docs/\#id=ysdg0100 [Accessed 10 Feb 2021].

36 RJR. nicotine and smoker satisfaction. 1987 Jan 03. Ness Motley law firm documents. Available: https://www.industrydocuments.ucsf.edu/tobacco/docs/\#id=jtpd0040 [Accessed 10 Feb 2021]. 